\title{
Chemopreventive and anticancer activities of indomethacin and vitamin D combination on colorectal cancer induced by 1,2-dimethylhydrazine in rats
}

\author{
TAREK M. OKDA ${ }^{1}$, SARY K. ABD-ELGHAFFAR ${ }^{2}$, \\ MOHAMED A. KATARY ${ }^{3,4}$ and MOHAMMAD M. ABD-ALHASEEB ${ }^{3}$
}

\author{
${ }^{1}$ Department of Biochemistry, Faculty of Pharmacy, Damanhour University, Damanhour, Behira 2251; \\ ${ }^{2}$ Department of Pathology and Clinical Pathology, Faculty of Veterinary Medicine, Assiut University, Assiut 71515; \\ ${ }^{3}$ Department of Pharmacology and Toxicology, Faculty of Pharmacy, Damanhour University, Damanhour, Behira 2251, Egypt; \\ ${ }^{4}$ Department of Oral Biology and Diagnostic Sciences, Augusta University, Augusta, GA 30912, USA
}

Received September 21, 2019; Accepted November 11, 2020

DOI: $10.3892 /$ br.2020.1403

\begin{abstract}
Several studies have revealed that the combination of indomethacin, a nonsteroidal anti-inflammatory drug (NSAID), and vitamin D reduces the risk of common types of cancers. Nonetheless, research on the deal concentrations used to test the impact of vitamin D on colon cancer is deficient. Along these lines, the aim of the present study was to evaluate the possible role of indomethacin and vitamin D as a preventative as well as a therapeutic operator for colon cancer growth induced by dimethylhydrazine (DMH) in male Albino rats. Fifty male albino rats were utilized in this examination; five groups were assigned from the animals (10 animals each): i) control group considered healthy animals; ii) carcinogen group that received DMH only; iii) prophylactic group; iv) vitamin $\mathrm{D}$ and indomethacin-treated group; and v) 5-flurouracil (5-FU) group. Western blot technique was used to determine the expression of carcinoembryonic antigen (CEA) and platelet-derived growth factor (PDGF). Overexpression of CEA and PDGF was noted in the carcinogenic group, while expression of CEA and PDGF in the prophylactic, vitamin D and indomethacin and 5-FU groups were markedly reduced. There was a likewise decline in tissue caspase- 3 activity and antioxidant parameters in the carcinogenic group, while, there was an increase in these markers in the 5-FU group as well as the prophylactic and vitamin D and indomethacin groups. The combination of vitamin D and indomethacin markedly reduced the incidence and severity of colon cancer. The molecular, biochemical and histopathological analysis related
\end{abstract}

Correspondence to: Dr Mohammad M. Abd-Alhaseeb, Department of Pharmacology and Toxicology, Faculty of Pharmacy, Damanhour University, Damanhour, Behira 2251, Egypt

E-mail: m.abdelhasseb@pharm.dmu.edu.eg

Key words: indomethacin, vitamin D, colorectal cancer, 1,2-dimethylhydrazine, carcinoembryonic antigen, platelet-derived growth factor with the oral administration of vitamin D and indomethacin display its capacity to limit the frequency of colorectal cancer.

\section{Introduction}

Colorectal cancer (CRC) is the third type of cancer that is commonly diagnosed in both men and women (1). Diet and life-style choices play a significant role in the development and prognosis of colon cancer (2). Colon cancer is a condition which is medically complex (1). This heterogeneity makes it difficult to assess which patients will most benefit from adjuvant therapy and hinders the development of new targeted agents. It is therefore important to gain more insight into the biological diversity of colon cancers, particularly with regard to clinical characteristics (3). Vitamin D is not really a vitamin but the precursor to the potent calcitriol steroid hormone that has widespread body-wide actions (4). Calcitriol controls various cellular pathways that can be used to assess the incidence and prognosis of cancer. Epidemiological studies have found a correlation between low serum levels of vitamin D with increased risk of colon cancer as well as inflammatory diseases including inflammatory bowel disease (4).

An individual's vitamin D status also depends on both diet and lifestyle. Garland and Garland (5) first proposed the correlation between vitamin D and colon cancer, finding that populations residing in the northeastern US had an increased incidence of colon cancer-related mortality relative to those residing in the southern US (6). Since then, sufficient levels of serum vitamin D have been associated with a lower incidence of colon cancer and lower mortality in patients with colon cancer (7). Adequate levels of serum vitamin D were also found to be associated with a lower risk of developing inflammatory diseases such as Crohn's disease, a colon cancer risk factor (8). Across different mouse models, vitamin D was found to have a protective effect against colon cancer (9). Yet, there is currently no awareness of the protective effect of vitamin $\mathrm{D}$ on inflammatory colon cancer. A previous study reported that a daily intake of 1,000 IU of vitamin D reduces the risk of CRC (10). 
Non-steroidal anti-inflammatory drugs (NSAIDs) minimize colon cancer incidence and reduce mortality in patients with colon cancer (11). NSAIDs are a very important class of drugs with several therapeutic applications in the treatment of osteoarthritis, some tumors and rheumatoid arthritis (12).

Among the various NSAIDs, indomethacin a standard cyclooxygenase (COX)-1 and -2 antagonist commonly used in the clinic for its potent anti-inflammatory and analgesic properties, has been shown to exert anti-CRC effects and is used to treat many solid and hematological malignancies in humans (13). Nonetheless, the body of evidence that indomethacin has anti-neoplastic efficacy in animal and in humans is one of the strongest among the numerous NSAIDs $(14,15)$.

Platelet-derived growth factor (PDGF) is a multifunctional polypeptide growth factor with significant biological effects ranging from mitogenic activity for mesenchymal cells to control of matrix metabolism, chemotactic and vasoactive properties, and regulation of immune or inflammatory reactions (16). PDGF plays an important role in several solid tumors. PDGF is a key target in cancer therapy, as it is mainly involved in cell migration and proliferation of stromal cells in cancers (16). PDGF encourages the development of new blood vessels that are necessary for tumor growth and metastasis (17).

The aim of the present study was to assess the protective role of the combined treatment of vitamin $\mathrm{D}$ and indomethacin in a 1,2-dimethylhydrazine (1,2-DMH)-induced CRC model in animals, and also to evaluate the combination of vitamin D and indomethacin for the treatment of CRC in animals. Finally, the study aimed to determine the effect of the combined treatment of vitamin $\mathrm{D}$ and indomethacin on the carcinoembryonic antigen (CEA) and PDGF expression in CRC.

\section{Materials and methods}

Chemicals. 1,2-DMH, indomethacin, vitamin D and 5-flurouracil (5-FU) were obtained from Sigma Aldrich Co. (Merck KGaA). Certain chemicals used, such as $\mathrm{NaCl}$, EDTA and Tris buffer were purchased from a local commercial source.

Treatment protocol and sampling. Male Albino rats $(\mathrm{n}=50)$ (5 weeks old, $150 \mathrm{~g}$ body weight) were obtained from the Faculty of Medicine's animal house at Assiut University (Assiut, Egypt). Animals were housed under controlled environmental conditions $\left(22 \pm 2^{\circ} \mathrm{C}\right.$ temperature, $50 \pm 5 \%$ humidity, $12 / 12 \mathrm{~h}$ light/dark cycle) and had free access to a typical grain diet and tap water. The research procedures were carried out in compliance with the National Institute of Health Guidelines for Animal Care (https:/grants.nih.gov/grants/olaw/guide-fo r-the-care-and-use-of-laboratory-animals.pdf) and approved (no. PHAB1827) by the Ethics Committee of the Faculty of Pharmacy, Assiut University (Assiut, Egypt).

The rats were divided into five groups, with 10 rats in each. i) The control group received $0.9 \%$ normal saline daily during the experimental period. ii) The carcinogenic group (DMH) was injected subcutaneously with $20 \mathrm{mg} / \mathrm{kg}$ of $1,2-\mathrm{DMH}$ once a week for 10 weeks as previously described (18) and rats were left to complete 18 weeks. iii) The prophylactic group was treated twice weekly with vitamin D [1,000 IU $(25 \mu \mathrm{g}) / \mathrm{rat} / \mathrm{p} . \mathrm{o}$.$] as previously described (19) and daily indo-$ methacin (2 mg/kg/p.o.) (18) for 4 weeks before 1,2-DMH injection and during the induction period for 10 weeks (14 weeks of prophylactic regimen) and rats were left to complete 18 weeks. iv) The combined treatment group was administrated subcutaneously with 1,2-DMH once weekly for 10 weeks, and then treated with vitamin D (1,000 IU (25 $\mu \mathrm{g}) / \mathrm{rat} / \mathrm{p}$. o.) (19) and daily indomethacin $(2 \mathrm{mg} / \mathrm{kg} / \mathrm{p} . \mathrm{o}$.) as previously described (20) for 8 weeks (18 weeks for treatment regimen). v) The 5-fluorouracil (5-FU) treatment group was injected subcutaneously with 1,2-DMH once weekly for 10 weeks, and then treated with 5 -FU (100 mg/kg/i.p.) as previously described (21) once weekly for 4 weeks (14 weeks for treatment regimen) and rats were left to complete 18 weeks.

The euthanasia of rats was carried out by ether. Ether anesthesia was induced in a glass jar containing a cotton wool pad soaked in anesthetic ether $30 \%$. Each rat was removed for orbital puncture when lightly anesthetized. The average time for anesthesia was $4.7 \mathrm{~min}$. The average volume of ether was $6.5 \mathrm{ml} / \mathrm{h}(22)$.

Blood samples were obtained and colons were rapidly excreted and used for RNA preparation or homogenization in $20 \mathrm{mM}$ Tris, $100 \mathrm{mM} \mathrm{NaCl}, 1 \mathrm{mM}$ EDTA and $0.5 \%$ Triton X-100 buffer. Colon homogenate protein content was calculated using Bradford reagent and bovine serum albumin (BSA) as standard. The mixture of protease inhibitors was added. Samples were aliquoted and stored at $-80^{\circ} \mathrm{C}$ until use.

Sodium dodecyl sulfate-polyacrylamide gel electrophoresis (SDS-PAGE) and western blotting. Protein concentration was determined per gram tissue, and $1 \mu \mathrm{l}$ of $10 \%$ tissue homogenate was added to $200 \mu \mathrm{l}$ of Bradford reagent. The absorbance was read at $595 \mathrm{~nm}$. Loading buffer [Tris HCL, sodium dodecyl sulfate (SDS), glycerol, bromophenol blue and $\beta$-mercaptoethanol] was boiled with $50 \mu \mathrm{g}$ tissue homogenate. All proteins became negatively charged and disulphide bridges in proteins were reduced. Using $12 \%$ polyacrylamide gel for electrophoresis, polyacrylamide gels were formed from the polymerization of two compounds, acrylamide and N,N-methylenebisacrylamide. Electrophoresis chamber (OWL. Separation Systems, Inc.; Ser. no: 128460) was filled with $1 \mathrm{X}$ running buffer and samples were loaded. Proteins were transferred from gel to nitrocellulose membrane. SDS-PAGE was carried out at $100 \mathrm{~V}$ for $2 \mathrm{~h}$. using the T-77 ECL semidry transfer unit (Amersham Biosciences; Ser. no. 20145681) for $2 \mathrm{~h}$, and the electro-transfer was completed. The membrane was blocked for $1 \mathrm{~h}$ in $5 \%$ milk solution $(5 \mathrm{~g}$ per $100 \mathrm{ml}$ of TBST buffer). The primary antibodies: rabbit polyclonal anti-CEA (Santa Cruz Biotechnology, Inc.; cat. no. sc-59875), anti-PDGF (Santa Cruz Biotechnology, Inc.; cat. no. sc-365805) and $\beta$-actin were used at 1:200 dilutions. The membrane was incubated with the primary antibodies for $1 \mathrm{~h}$ at room temperature with constant agitation. Peroxidase labeled anti-rabbit antibody (secondary antibody) was acquired from Amersham $^{\text {TM }}$ (GE Healthcare) (cat. no. NIF824) and was used at a dilution 1:3,000 and incubated with the membrane for $2 \mathrm{~h}$. Detection kit (ECL-Plus) was obtained from Amersham ${ }^{\mathrm{TM}}$ Company (cat no. RPN2108). They were incubated for $5 \mathrm{~min}$ at room temperature in the dark. The entire membrane was covered by detection solution. Image $\mathbf{J}$ (Image $\mathbf{J} 2 \mathrm{x} .8$ ) 
(National Institutes of Health, Bethesda, MD, USA) was used to calculate peak size.

Determination of tissue caspase-3 activity. Caspase-3 proteolytic activity was calculated using a calorimetric assay kit (Caspase-3/CPP32, ApoTarget, Colorimetric Protease Assay kit; Biosource Int.). Determination of caspase-3 proteolytic activity was carried out using a modified procedure as previously described (23). Cytosolic extracts were prepared by homogenization of the colon tissue $(50 \mathrm{mg})$ in lysis buffer. Subsequently, the homogenates were centrifuged at $10,000 \mathrm{x} \mathrm{g}$ for $10 \mathrm{~min}$. An amount of $50 \mu \mathrm{l}$ of reaction buffer was added to $50 \mu \mathrm{l}$ of each sample. A maximum of $10 \mu \mathrm{l}$ of DEVD-pNA substrates was applied to the tubes and incubated at $37^{\circ} \mathrm{C}$ for $1 \mathrm{~h}$. Samples were read at $405 \mathrm{~nm}$ using Shimadzu Spectrophotometer, UV, 1201. Results are expressed as means \pm SEM of three separate trials (triplicate).

Determination of oxidative stress biomarkers. Lipid peroxidation determination is dependent on the formation of malondialdehyde (MDA) that reacts with thiobarbituric acid to produce a colored material. The latter can be calorimetrically calculated. Lipid peroxide levels in the tissues were assessed as previously described (23). The results are expressed as means \pm SEM of three separate trials.

Nitric oxide (NO) levels in the tissues were measured using a previously described method (24). Data are expressed as means \pm SEM of three separate experiments.

Tissue total antioxidant levels were estimated by total antioxidant capacity assay Kit T-AOC (cat. no. ab65329; Abcam). The data are expressed as means \pm SEM of three separate trials. This ELISA kit uses Sandwich-ELISA as the method. An amount of $40 \mu \mathrm{l}$ of sample dilution buffer was mixed with $10 \mu \mathrm{l}$ of sample and incubated for $30 \mathrm{~min}$ at $37^{\circ} \mathrm{C}$. Then the wash solution was aspirated and refilled and discarded after resting for $30 \mathrm{sec}$. The washing procedure was repeated 5 times. Horseradish peroxidase (HRP)-conjugated reagent $(50 \mu \mathrm{l})$ was added to each well except the blank control well and incubated for $30 \mathrm{~min}$ at $37^{\circ} \mathrm{C}$. The washing procedure was repeated 5 times. Chromogen solution $\mathrm{A}(50 \mu \mathrm{l})$ and chromogen solution B $(50 \mu \mathrm{l})$ were added to each well and mixed with gentle shaking and incubated at $37^{\circ} \mathrm{C}$ for $15 \mathrm{~min}$. Stop solution $(50 \mu \mathrm{l})$ was added to each well to terminate the reaction. The samples were read at $450 \mathrm{~nm}$ using a microtiter plate reader.

Histopathological examinations. The colons were dissected and washed with $0.9 \%$ sterile saline solution. Each colon was cut into small pieces and kept in neutral buffer formalin. Formalin-fixed colon samples were moved to $70 \%$ ethanol and coated in paraffin. Tissue sections were treated at room temperature for $15 \mathrm{~min}$ with hematoxylin and eosin (H\&E) and tested for pathological changes under an optical microscope.

Statistical analysis of the data. Data analysis was carried out using Graphpad Instat version 3 (GraphPad Software, Inc.). The results are expressed as mean $\pm \mathrm{SD}$ and $\mathrm{P}<0.05$ was assigned as indicative of a statistical significant difference. Multiple comparisons were performed using one-way ANOVA approach followed by Tukey as a multiple comparison post hoc ANOVA test.

\section{Results}

Expression of CEA and PDGF. Fig. 1A-C shows the expression of CEA and PDGF protein by western blot analysis in all experimental stages. A significant increase in CEA expression in the carcinogenic group (40\%) (Fig. A and D) was noted when compared with the control group (10\%). In contrast, the expression level was significantly decreased in the 5-FU group when compared with the carcinogenic group and the expression level was decreased but with a lower degree in both the prophylactic and vitamin D + indomethacin (Treated) groups. Furthermore, the expression of PDG (Fig. 1A and E) in the carcinogenic group reached a maximum peak while its expression was significantly reduced in the other groups (5-FU, prophylactic and vitamin D + indomethacin (Treated) groups).

Tissue caspase- 3 activity. In the carcinogenic group, there was a significant decrease in caspase- 3 levels compared to the control group. This significant reduction was reversed as an increase in caspase-3 levels was noted in the prophylactic group, vitamin D + indomethacin (Treated group) and 5-FU group when compared with the carcinogenic group (Fig. 2).

Oxidative stress levels. Table I summarizes the oxidative stress levels in the different groups. The carcinogenic group exhibited a significant increase in both NO and MDA levels when compared to the control group. The prophylactic, vitamin $\mathrm{D}+$ indomethacin and 5 -FU groups, on the other hand, exhibited significantly reduced levels of oxidative stress induced by NO and MDA.

Furthermore, total antioxidant capacity (TAC) was significantly reduced in the carcinogenic group when compared with the control group, while the prophylactic, vitamin D + indomethacin and 5-FU groups exhibited significantly increased TAC when compared with the carcinogenic group (Table I).

Histopathological results. To assess the changes in colon cells after DMH, vitamin D + indomethacin and 5-FU administration, H\&E-stained slides were examined. Colon section from the rats in the control group shows normal histological structure (Fig. 3A). On the other hand, the carcinogenic group demonstrated proliferation of tumor cells from the epithelial layer infiltrating the submucosa. The tumor cells (arrows) are polyhedral cells with hyperchromatic nuclei (Fig. 3B). The prophylactic group showed more or less normal histological appearance (Fig. 3C). Furthermore, the vitamin D + indomethacin group showed infiltrating tumor cells undergoing either necrosis (arrow) or apoptosis (double arrows) with infiltration of mast cells (arrow heads) (Fig. 3D). Finally, the 5-FU group showed colon adenocarcinoma with tumor cell necrosis (arrows) and heavy infiltration with mast cells (arrow heads) (Fig. 3E).

\section{Discussion}

The anticancer activity of indomethacin, a standard cyclooxygenase (COX)-1 and -2 antagonist commonly used in the clinic for its potent anti-inflammatory and analgesic properties, has been described both in vitro as well as in vivo (25). Several experimental and clinical studies have reported that the pathways 


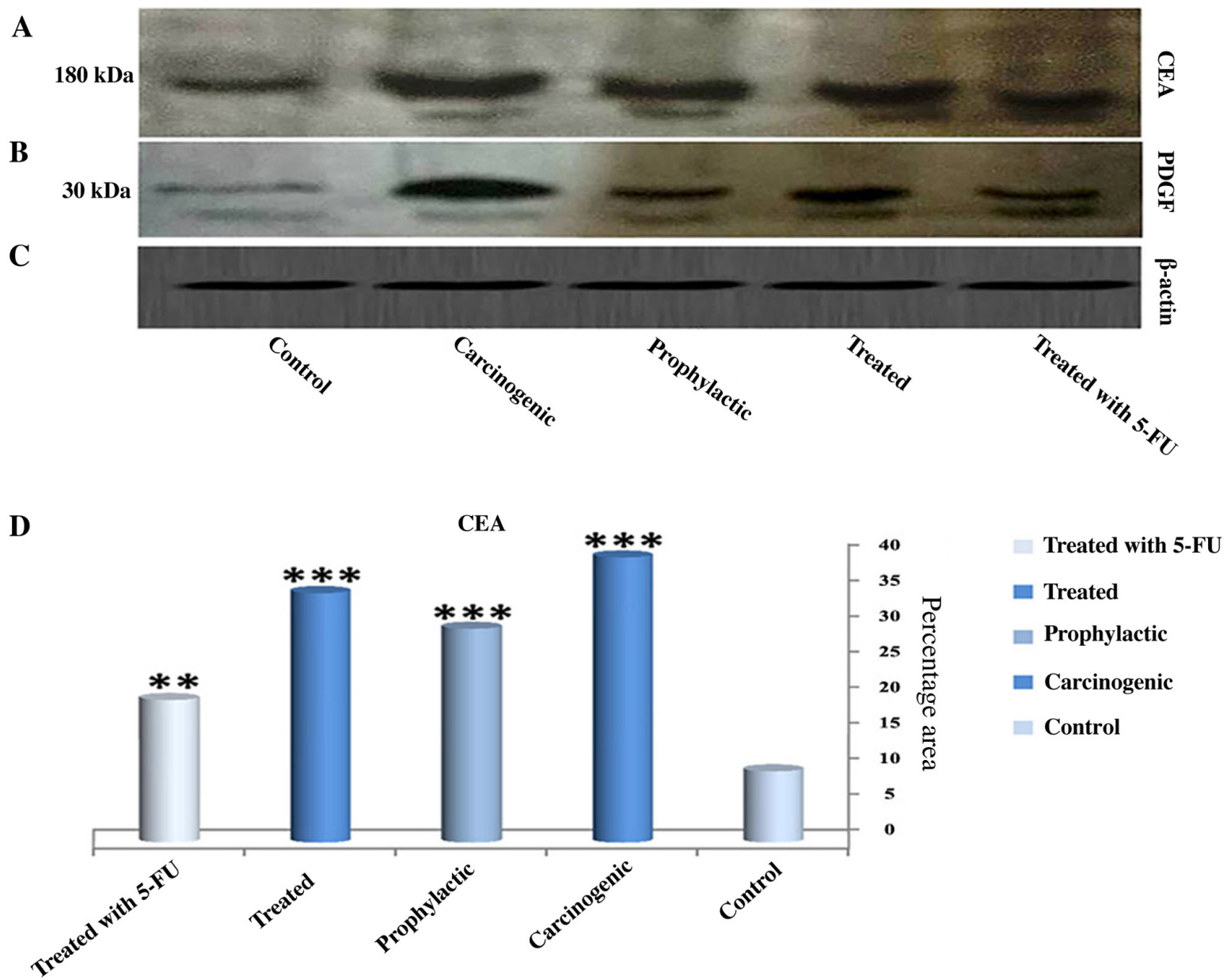

$\mathbf{E}$

PDGF

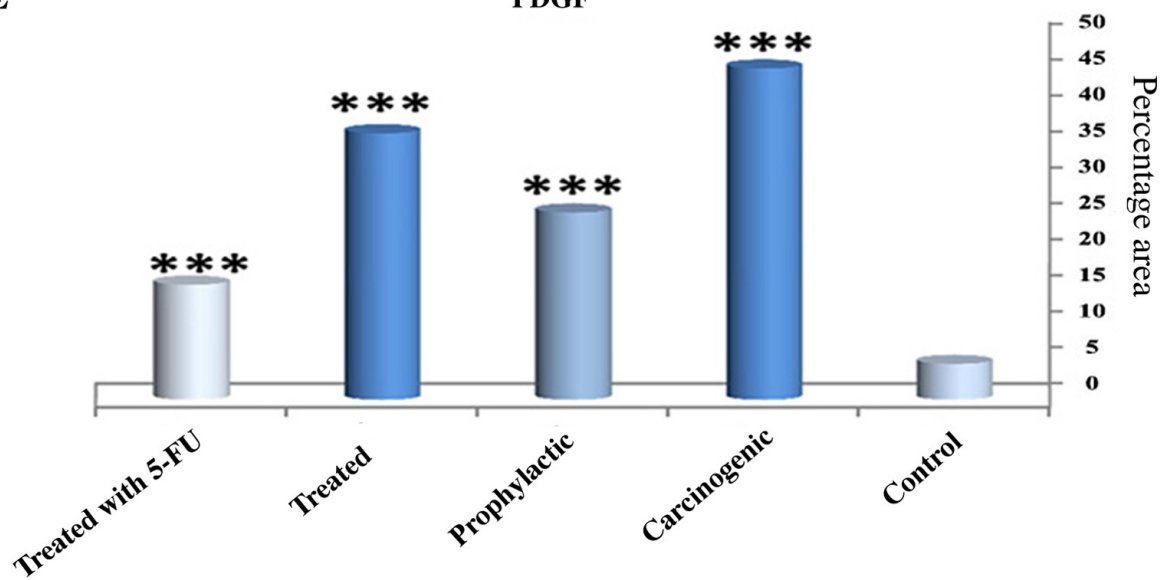

\author{
Treated with 5-FU \\ Treated \\ Prophylactic \\ Carcinogenic \\ Control
}

Figure 1. Effect of the combination of indomethacin and vitamin D on CEA and PDGF levels in all experimental groups. (A-C) The expression of CEA, PDGF and $\beta$-actin were determined by western blot technique in all groups. The expression levels of CEA and PDGF were increased markedly in the carcinogenic group, while its levels were decreased in the prophylactic group and treated group (with vitamin D and indomethacin) and 5-FU groups. (D) Quantification of the expression of CEA in all experimental groups. (E) Quantification of the expression of PDGF in all experimental groups. Results are expressed as means \pm SEM of three separate times. ${ }^{* * *} \mathrm{P}<0.001$ and ${ }^{* *} \mathrm{P}<0.01$, significant difference compared to the control group. CEA, carcinoembryonic antigen; PDGF, platelet-derived growth factor; 5-FU, 5-flurouracil.

involved in the therapeutic effects of indomethacin and vitamin D in colon cancer are still limited (26). The present study found that combined treatment of vitamin D and indomethacin was associated with a lower risk of colon cancer in a rat model. In addition, the results showed that the combination of indomethacin and vitamin D had anti-colon cancer effect.
Our findings concerning the antitumor activity of vitamin D are agreed with those of Feldman et al (27), who stated that calcitriol controls a variety of cellular pathways that may have a role to play in evaluating cancer risk and prognosis. It is also proposed that vitamin D deficiency raises the risk of developing cancer and that reducing the shortage and adding 
Table I. Effects of Vitamin D and indomethacin combination on NO, MDA and total antioxidants.

\begin{tabular}{|c|c|c|c|c|c|}
\hline Biochemical indices & Control & Carcinogenic & Prophylactic & Vitamin D + indomethacin & $5-\mathrm{FU}$ \\
\hline NO $(\mu \mathrm{M} / \mathrm{g}$ wet tissue $)$ & $28.89 \pm 3.07$ & $69.24 \pm 4.95^{\mathrm{a}}$ & $45.11 \pm 3.10^{\mathrm{b}}$ & $51.08 \pm 3.29^{\mathrm{b}}$ & $42.88 \pm 4.91^{b}$ \\
\hline $\operatorname{MDA}(\mu \mathrm{M} / \mathrm{g}$ wet tissue $)$ & $1.65 \pm 0.95$ & $6.22 \pm 0.58^{\mathrm{a}}$ & $3.01 \pm 1.04^{\mathrm{b}}$ & $3.71 \pm 0.642^{\mathrm{b}}$ & $3.48 \pm 0.92^{\mathrm{b}}$ \\
\hline TAC (U/mg protein) & $29.94 \pm 4.54$ & $12.13 \pm 2.66^{\mathrm{a}}$ & $23.87 \pm 3.1^{\mathrm{b}}$ & $19.77 \pm 2.84^{\mathrm{b}}$ & $21.98 \pm 3.30^{\mathrm{b}}$ \\
\hline
\end{tabular}

Results are expressed as mean \pm SD. One way ANOVA was used to analyze data followed by Tukey-Kramer test as post hoc test. ${ }^{\text {SSignificant }}$ from the control group at $\mathrm{P}<0.001$. ${ }^{\mathrm{b}}$ Significant from the carcinogenic group at $\mathrm{P}<0.001$. NO, nitric oxide; MDA, malondialdehyde; TAC, total antioxidant capacity; 5-FU, 5-flurouracil.

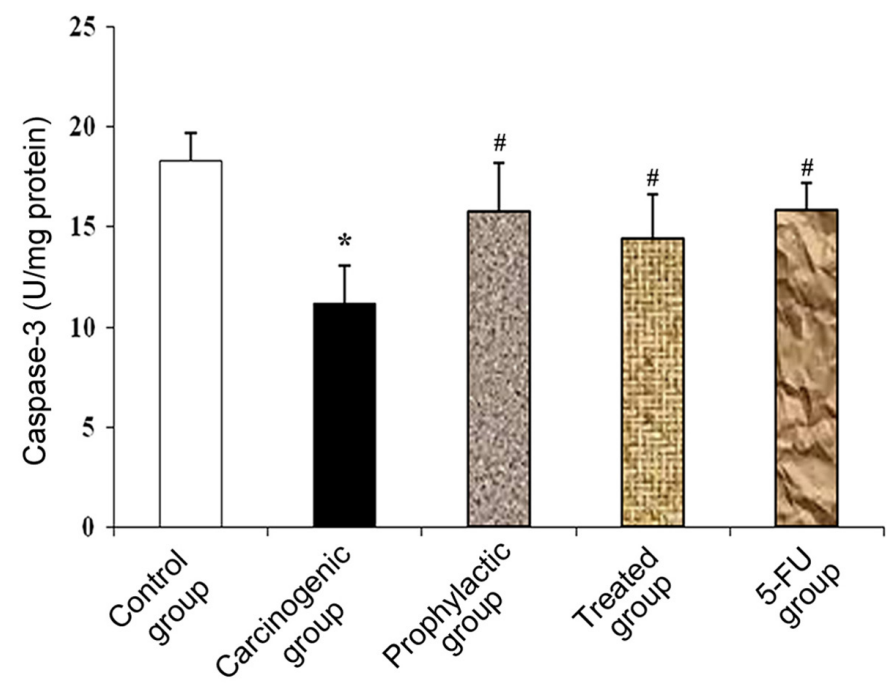

Figure 2. Effect of combined vitamin D and indomethacin treatment on tissue caspase-3 activity. Data are expressed as mean \pm SD of three separate trials. The analysis of data was performed using one-way ANOVA approach by Tukey test as post ANOVA hoc test. ${ }^{*} \mathrm{P}<0.001$, significant difference compared to the control group and ${ }^{\#} \mathrm{P}<0.001$, significant difference compared to the carcinogenic group.
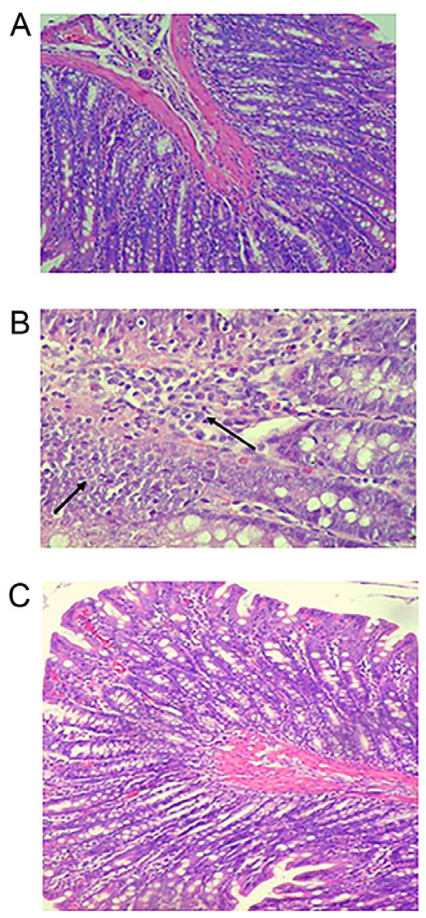
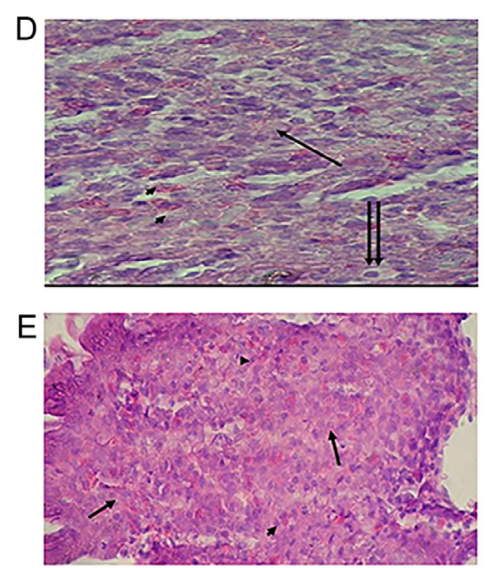

Figure 3. Effect of combined vitamin D and indomethacin treatment on histopathological changes in the rat colon. Slides were stained using H\&E. (A) Control group (magnification, x10). (B) Carcinogenic group (magnification, x40). (C) Prophylactic group (magnification, 10). (D) Vitamin D + indomethacin group (magnification, x40). (E) 5-FU group (magnification, x40). H\&E, hematoxylin and eosin; 5-FU, 5-flurouracil. 
supplementation of vitamin D could be an inexpensive, effective and safe way to reduce cancer incidence and improve cancer prognosis and outcome.

Colon receptors contain vitamin D receptors and vitamin D binds to these receptors. This may prevent the growth of oncogenes and may prevent the spread of cancer cells to other parts of the body. It is therefore believed that vitamin D can help protect against colorectal cancer (CRC) by reducing the likelihood that cancer cells can develop and spread (10).

Correlations between high vitamin D levels and the reduced risk and progression of CRC are still being investigated and more studies are needed (28). This is in agreement with the results of the present study. We hypothesized that the anticancer activity of indomethacin and vitamin D may involve enhancement of apoptotic markers and the reduction of oxidative stress markers.

CEA is a well-known soluble tumor marker and an onco-fetal glycoprotein. Although its existence is primarily confined to the large intestine in healthy tissues, it is overexpressed in most gastrointestinal malignancies, breast cancer, thyroid cancer and lung cancer (29). The present study proposed that there are various colon cancer markers such as CEA and PDGF. Thus, in the present study, both CEA and PDGF expression levels were increased in the carcinogenic group due to inflammation or cancer progression in the CRC tissues, while their levels were reduced during treatment with indomethacin and vitamin D. Such results indicate that indomethacin and vitamin D combination therapy decreases the severity of inflammation and colon cancer.

Pan et al (30) indicated that PDGF is known to encourage the development of new blood vessels that are essential to the growth and metastasis of tumors. PDGF in portal vein blood tumor drainage may be useful predictive factors for CRC synchronous liver metastasis. Such results are confirmed by our findings which demonstrated increased PDGF in the development of inflammation and cancer. PDGF is currently reported as a major inflammatory growth factor following acute and chronic tissue injury playing a central role in the repair process (25).

In this research, indomethacin and vitamin D are associated with biochemical and morphological changes, including apoptosis enhancement and oxidative stress reduction. Thus, the activity of caspase- 3 was estimated to demonstrate the possible mechanisms of indomethacin and vitamin D-mediated anti-inflammatory and/or antitumor effect.

The present study reported that the determination of caspase-3 activity has revealed that during inflammation and progression of cancer stage, levels of caspase- 3 are markedly decreased. On the other hand, its levels were increased in the indomethacin and vitamin D treatment group. These results are in harmony with the results reported by Jung et al (31), Okda et al (32) and Katary et al (33). The authors showed that caspase-3, which is a pro-apoptotic protein, was increased after the damage of hepatocellular carcinoma which occurred by $\mathrm{CCl} 4$, while its level was decreased due to the partial repairing occurred.

In the present study, we observed increased serum NO and MDA levels in the carcinogenic group and decreased levels in the indomethacin + vitamin D and 5-FU treatment groups by reducing oxidative stress markers. Decreased levels of oxidative stress factors were observed in the prophylactic and treated groups. There was a statistically significant increase in the total oxidative stress markers (NO and MDA) in colon tissues of the carcinogenic group compared to the control group. Histopathological examinations were performed. The results of the histopathological examinations confirmed that there was marked improvement in colon cells in the prophylactic and treatment groups. Unfortunately, the present study had a histopathological limitation because the weight and numbers of tumors were not calculated.

In conclusion, in the present study, the use of vitamin D and indomethacin significantly reduced colon cancer incidence. Vitamin D is one of natural antioxidant which reduces oxidative stress markers and inflammation. Biochemical and molecular research associated with the administration of vitamin $\mathrm{D}$ and indomethacin shows that it has the ability to reduce the occurrence of colon carcinomas. This combination eliminates toxic side effects of chemotherapy and decreases colon cancer incidence.

\section{Acknowledgements}

Not applicable.

\section{Funding}

No funding was received.

\section{Availability of data and materials}

The datasets used and/or analyzed during the current study are available from the corresponding author on reasonable request.

\section{Authors' contributions}

TMO and MMAA conceived the research concept, experiment design and methodology. MMAA and MAK carried out the animal modeling and animal handling. TMO performed the western blot analysis. TMO, MK and MMAA analyzed and interpreted the results. SKAE performed the histological examination and analysis of the colon sections. TMO and SKAE drafted the manuscript. MMAA was a major contributor in editing and writing the manuscript. All authors read and approved the final manuscript.

\section{Ethics approval and consent to participate}

The research procedures were performed in compliance with the National Institute for Animal Care Health Guidelines and approved by the Faculty of Pharmacy's Ethics Committee, Assiut University (Assiut, Egypt).

\section{Patient consent for publication}

Not applicable.

\section{Competing interests}

The authors declare that they have no competing interests. 


\section{References}

1. Sung JJY, Chiu HM, Jung KW, Jun JK, Sekiguchi M, Matsuda T and Kyaw MH: Increasing trend in young-onset colorectal cancer in Asia: more cancers in men and more rectal cancers. Am J Gastroenterol 114: 322-329, 2019.

2. Lofano K,Principi M, Scavo MP,Pricci M, Ierardi E and Di Leo A: Dietary lifestyle and colorectal cancer onset, recurrence, and survival: Myth or reality? J Gastrointest Cancer 44: 1-11, 2013.

3. Wolpin BM and Mayer RJ: Systemic treatment of colorectal cancer. Gastroenterology 134: 1296-1310, 2008.

4. Meeker S, Seamons A, Paik J, Treuting PM, Brabb T, Grady WM and Maggio-Price L: Increased dietary vitamin D suppresses MAPK signaling, colitis, and colon cancer. Cancer Res 74 4398-4408, 2014.

5. Garland CF and Garland FC: Do sunlight and vitamin D reduce the likelihood of colon cancer? Int J Epidemiol 9: 227-231, 1980

6. Deeb KK, Trump DL and Johnson CS: Vitamin D signalling pathways in cancer: Potential for anticancer therapeutics. Nat Rev Cancer 7: 684-700, 2007.

7. $\mathrm{Ng} \mathrm{K}$, Meyerhardt JA, Wu K,FeskanichD,Hollis BW, Giovannucci EL and Fuchs CS: Circulating 25-hydroxyvitamin D levels and survival in patients with colorectal cancer. J Clin Oncol 26 2984-2991, 2008.

8. Ananthakrishnan AN, Khalili H, Higuchi LM, Bao Y, Korzenik JR, Giovannucci EL, Richter JM, Fuchs CS and Chan AT: Higher predicted vitamin D status is associated with reduced risk of Crohn's disease. Gastroenterology 142: 482-489, 2012.

9. Fichera A, Little N, Dougherty U, Mustafi R, Cerda S, Li YC, Delgado J, Arora A, Campbell LK, Joseph L, et al: A vitamin D analogue inhibits colonic carcinogenesis in the AOM/DSS model. J Surg Res 142: 239-245, 2007.

10. Gorham ED, Garland CF, Garland FC, Grant WB, Mohr SB Lipkin M, Newmark HL, Giovannucci E, Wei M and Holick MF: Optimal vitamin D status for colorectal cancer prevention: A quantitative meta analysis. Am J Prev Med 32: 210-216, 2007.

11. Rayyan Y, Williams J and Rigas B: The role of NSAIDs in the prevention of colon cancer. Cancer Invest 20: 1002-1011, 2002.

12. Rao P and Knaus EE: Evolution of nonsteroidal anti-inflammatory drugs (NSAIDs): Cyclooxygenase (COX) inhibition and beyond. J Pharm Pharm Sci 11: 81s-110s, 2008.

13. Woo JK, Kang JH, Jang YS, Ro S, Cho JM, Kim HM, Lee SJ and Oh SH: Evaluation of preventive and therapeutic activity of novel non-steroidal anti-inflammatory drug, CG100649, in colon cancer: Increased expression of TNF-related apoptosis-inducing ligand receptors enhance the apoptotic response to combination treatment with TRAIL. Oncol Rep 33: 1947-1955, 2015.

14. Vane JR and Botting RM: Mechanism of action of anti-inflammatory drugs. Adv Exp Med Biol 433: 131-138, 1997.

15. Lai SW and Liao KF: Aspirin use after diagnosis improves survival in older adults with colon cancer. J Am Geriatr Soc 61: 843-844, 2013.

16. Peyre M, Salaud C, Clermont-Taranchon E, Niwa-Kawakita M, Goutagny S, Mawrin C, Giovannini $\mathrm{M}$ and Kalamarides $\mathrm{M}$ : PDGF activation in PGDS-positive arachnoid cells induces meningioma formation in mice promoting tumor progression in combination with Nf2 and Cdkn2ab loss. Oncotarget 6: 32713-32722, 2015.

17. Zhou J, Tang ZY, Fan J, Wu ZQ, Li XM, Liu YK, Liu F, Sun HC and Ye SL: Expression of platelet-derived endothelial cell growth factor and vascular endothelial growth factor in hepatocellular carcinoma and portal vein tumor thrombus. J Cancer Res Clin Oncol 126: 57-61, 2000
18. Sumiyoshi $\mathrm{H}$ and Wargovich MJ: Chemoprevention of 1,2-dimethylhydrazine-induced colon cancer in mice by naturally occurring organosulfur compounds. Cancer Res 50: 5084-5087, 1990

19. Lappe JM, Travers-Gustafson D, Davies KM, Recker RR and Heaney RP: Vitamin D and calcium supplementation reduces cancer risk: Results of a randomized trial. Am J Clin Nutr 85: 1586-1591, 2007.

20. Quidville V, Segond N, Pidoux E, Cohen R, Jullienne A and Lausson S: Tumor growth inhibition by indomethacin in a mouse model of human medullary thyroid cancer: Implication of cyclooxygenases and 15-hydroxyprostaglandin dehydrogenase. Endocrinology 145: 2561-2571, 2004.

21. Gupta S, Khan H, Barik S and Negi MP: Clinical benefits of concurrent capecitabine and cisplatin versus concurrent cisplatin and 5-flurouracil in locally advanced squamous cell head and neck cancer. Drug Discov Ther 7: 36-42, 2013.

22. Miranda EG, Nascimento VP, Waisberg DR, Sousa MW, Lima MF, Silva DS and Waisberg J: Inhalation anesthesia equipment for rats with provision of simultaneous anesthetic and oxygen. Acta Cir Bras 26: 140-143, 2011.

23. Buege JA and Aust SD: Microsomal lipid peroxidation. Methods Enzymol 52: 302-310, 1978

24. van Bezooijen RL, Que I, Ederveen AG, Kloosterboer HJ, Papapoulos SE and Löwik CW: Plasma nitrate+nitrite levels are regulated by ovarian steroids but do not correlate with trabecular bone mineral density in rats. J Endocrinol 159: 27-34, 1998.

25. Martin P and Nunan R: Cellular and molecular mechanisms of repair in acute and chronic wound healing. Br J Dermatol 173: 370-378, 2015.

26. Hull MA, Gardner SH and Hawcroft G: Activity of the non-steroidal anti-inflammatory drug indomethacin against colorectal cancer. Cancer Treat Rev 29: 309-320, 2003.

27. Feldman D, Krishnan AV, Swami S, Giovannucci E and Feldman BJ: The role of vitamin D in reducing cancer risk and progression. Nat Rev Cancer 14: 342-357, 2014.

28. Welsh J: Cellular and molecular effects of vitamin D on carcinogenesis. Arch Biochem Biophys 523: 107-114, 2012.

29. Ojima T, Iwahashi M, Nakamura M, Matsuda K, Nakamori M, Ueda K, Naka T, Ishida K, Primus FJ and Yamaue H: Successful cancer vaccine therapy for carcinoembryonic antigen (CEA)-expressing colon cancer using genetically modified dendritic cells that express CEA and T helper-type 1 cytokines in CEA transgenic mice. Int J Cancer 120: 585-593, 2007.

30. Pan HD, Peng YF, Xiao G and Gu J: High levels of serum platelet-derived growth factor-AA and human epidermal growth factor receptor-2 are predictors of colorectal cancer liver metastasis. World J Gastroenterol 23: 1233-1240, 2017.

31. Jung MY, Kang HJ and Moon A: Capsaicin-induced apoptosis in SK-Hep-1 hepatocarcinoma cells involves Bcl-2 downregulation and caspase-3 activation. Cancer Lett 165: 139-145, 2001.

32. Okda TM, Abd-Alhaseeb MM, Barka K and Ragab NM: Ginger potentiates the effects of silymarin on liver fibrosis induced by CCL4: The role of galectin-8. Eur Rev Med Pharmacol Sci 23: 885-891, 2019.

33. Katary MA, Abdelsayed R, Alhashim A, Abdelhasib M and Elmarakby AA: Salvianolic acid B slows the progression of breast cancer cell growth via enhancement of apoptosis and reduction of oxidative stress, inflammation, and angiogenesis. Int J Mol Sci 20: 5653,2019

This work is licensed under a Creative Commons Attribution-NonCommercial-NoDerivatives 4.0 International (CC BY-NC-ND 4.0) License. 